University of Nebraska - Lincoln

DigitalCommons@University of Nebraska - Lincoln

\title{
$5-2010$
}

\section{Managing BPO Service Workers in India: Examining Hope on Performance Outcomes}

\author{
Gwendolyn M. Combs \\ University of Nebraska - Lincoln, gcombs2@unl.edu \\ Rachel Clapp-Smith \\ Purdue University Calumet, rachel.smith@purduecal.edu \\ Sucheta Nadkarni \\ Drexel University, ssn28@drexel.edu
}

Follow this and additional works at: https://digitalcommons.unl.edu/managementfacpub

Part of the Management Sciences and Quantitative Methods Commons

Combs, Gwendolyn M.; Clapp-Smith, Rachel; and Nadkarni, Sucheta, "Managing BPO Service Workers in India: Examining Hope on Performance Outcomes" (2010). Management Department Faculty Publications. 56.

https://digitalcommons.unl.edu/managementfacpub/56

This Article is brought to you for free and open access by the Management Department at DigitalCommons@University of Nebraska - Lincoln. It has been accepted for inclusion in Management Department Faculty Publications by an authorized administrator of DigitalCommons@University of Nebraska - Lincoln. 


\title{
Managing BPO Service Workers in India: Examining Hope on Performance Outcomes
}

\author{
Gwendolyn M. Combs, Rachel Clapp-Smith, and Sucheta Nadkarni \\ Corresponding author - Gwendolyn M. Combs, Associate Professor of Management, College of Business \\ Administration, University of Nebraska-Lincoln, 274 CBA P.O. Box 88049I, Lincoln, NE 68588-049I; tel \\ 402 472-39I5, fax 402 472-5855, email gcombs2@unl.edu
}

\begin{abstract}
Much attention has been given to the explosion in business process outsourcing (BPO) operations in India. Little concern, however, has been paid to the performance of Indian service workers in these fast-paced and sometimes turbulent environments. Using a sample of 160 service workers from a privately held BPO firm in India, we examine the relationship between Indian service workers' hope and their performance outcomes. Regression and structural equation model analyses indicated a significant positive relationship between Indian service workers' levels of hope and their performance. These promising results highlight the importance of measuring and managing employee hope to maximize employee productivity and performance. By effectively developing and managing levels of employee hope, Indian BPO firms can effectively combat employee problems such as attrition, stress, and burnout that have plagued the BPO industry. Hope may also help mitigate the influence of aspects of Indian culture on human resource management practices in Indian BPOs.
\end{abstract}

Keywords: hope, performance, international management, performance management, BPO industry, attrition, stress, burnout

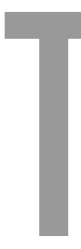

he majority of major organizations in the United States have turned to outsourcing and offshoring internal operations as a way to improve organizational performance (Budhwar \& Sparrow, 2002; Evan, Pucik, \& Barsoux, 2002; Panayotopoulou, Bourantas, \& Papalexandris, 2003). Information processing and call center activities of manufacturing, financial, and service organizations have moved offshore to Asian and Pacific Rim countries in record numbers. India, with its ready source of English-speaking, highly educated, and technologically trained workers, has become the location of choice for business processing outsourcing (BPO) functions of multinational clients (Kripalani, Engardio, \& Hamm, 2003; Pio, 2007). The proliferation of outsourcing to India has resulted in robust GDP growth rates that place great demands on this emerging economic power (Budhwar, Varma, Singh, \& Dhar, 2006; "Emerging-market indicators," 2005). Indian BPO firms often serve a broad spectrum of client firms including market research agencies, consulting 
firms, investment banks, legal firms, pharmaceuticals, and automotive companies (Budhwar, Luthar, \& Bhatnagar, 2006; Thite \& Russell, 2009). India is a dominant offshore BPO service provider, accounting for $75 \%$ of offshore delivery value (Nag, 2004), with total 2006-2007 export revenue of \$8.3 billion (Raman, Budhwar, \& Balasubramanian, 2007).

The increased demand for business process operations has created a high-velocity industry where change can be sweeping and ongoing (Srivastava, 2009). Additionally, India stands as a prominent prototype for integrating foreign workers into the competitive strategy of U.S. organizations (Pio, 2007). As Indian workers beResearch on come more entrenched and connected to foreign organizations, hope and other it is important for both the client firm and the BPO operapositivity constructs tion to identify applicable human resource development and must move from high performance management practices (Budhwar \& Sparrow, an ethnocentric 2002; Evan et al., 2002).

From a human resource manperspective to a agement (HRM) perspective, it is important to determine factors that have high potential to influence the productivity of Incultural experiences dian BPO workers involved in the expanding, high-flux outsourcing sector (Budhwar, Varma et al., 2006). Moreover,

(Budhar \& Sparrow, it is critical to ascertain the developmental nature of such factors in order to sustain employees' productive capacity and replicate positive performance (Khandekar \& Sharma, 2006). To be strategic, HRM practices must align with and fundamentally support organizational performance and profitability both domestically and internationally (Panayotopoulou et al., 2003).

Central to developing performance-based HRM practices is the need to examine employee psychological constructs that have been linked to employee performance, productivity, and satisfaction. Several psychological constructs are reflected as positive strengths that can help individuals optimize situational outcomes (Seligman \& Csikszentmihalyi, 2000; Snyder, 2000). How employees manage potentially negative components of their work environments can be impacted by their individual capacity to identify and develop strengths to overcome potentially negative workplace characteristics (Luthans, 2002a, 2002b). Additionally, understanding cognitive interpretations of cultural norms is important to developing and implementing effective HRM practices (Budhwar \& Sparrow, 2002). By understanding and managing these performance-related psychological constructs, Indian BPO firms may effectively boost organizational performance by reducing HRM problems such as employee attrition, turnover, stress, and burnout (Khandekar \& Sharma, 2006). We propose that one such psychological construct - hope-has been linked to performance but has been overlooked as a resource for HRM practices in India.

Hope is one of several psychological strengths that have been linked to employee performance and satisfaction with both U.S. samples (Luthans, Avolio, Avey, \& Norman, 2007; Youssef \& Luthans, 2007) and Chinese samples (Luthans, Avey, ClappSmith, \& Li, 2008; Luthans, Avolio, Walumbwa, \& $\mathrm{Li}, 2005)$. As presented later in more detail, we selected hope for this study because it describes critical performance determinants as goal formation, persistence toward accomplishing goals, and positive affective responses to meaningful life experiences (Luthans, 2002a, 2002b; Luthans, Youssef, \& Avolio, 2007). These factors are especially relevant to the Indian BPO context, which is characterized by factors that are likely to both inhibit (e.g., psychological stress due to language and cultural barriers) and enhance (e.g., high growth levels and job opportunities) employee hope. By effectively managing employee hope, BPO firms could possibly reduce the high level of employee attrition that has plagued India's changing BPO industry. Consequently, elements of employee hope could be important to sustaining performance in the Indian BPO industry. Studies on hope (S. J. Peterson \& Luthans, 2003) suggest the importance of the construct as a critical influence on employee performance. 
The purpose of this study, therefore, is to explore the relationship of Indian service workers' hope and their performance outcomes as reflected by commission and supervisor performance ratings. This study also contributes to our understanding of hope in new cultural domains and its global relevance for developing human resources and sustaining high impact performance.

More generally, identifying high performance human resource practices and their applicability for diverse employee backgrounds is vital to the continued success of emergent market sectors in India (Martin \& Beaumont, 1998; Pio, 2007). To establish the utility of hope as a valid performance indicator in global work environments, the generalizability of the construct across domains and cultures must be examined further (Snyder \& Lopez, 2002). Except for the few previously cited Chinese studies, investigating the relationship of employee hope to performance has been limited to a Western (primarily U.S.) context. Research on hope and other positivity constructs must move from an ethnocentric perspective to a broader base of cultural experiences and expectations (Budhwar \& Sparrow, 2002).

India, with its global presence in BPO markets and research and development centers, provides an important context to consider the extent, type, and depth of the relationship between hope and performance in other (non-Western and non-U.S.) cultures and settings. Specifically, examining hope in a sample of Indian service workers can contribute to the generalizability of the construct and its impact on performance. Additionally, the Indian sample allows us to examine hope within the context of different political structures, religious values, and economic systems (Budhwar \& Sparrow, 2002; House \& Javidan, 2004). Implications for global managers and future directions are presented and discussed.

\section{The Indian Cultural Context}

Important to the findings of this study are the contextual and environmental factors that may bear on the function of hope in India. Prior to discussing the theoretical foundation of hope, we first provide a brief overview of India and the im- portance that hope may have in this dramatically emerging global market.

One of India's greatest resources is its population of more than one billion people, growing at a rate of $1.9 \%$ yearly (Budhwar, 2001). A slight majority $(61 \%)$ of the population is literate (CIA World Factbook, 2009), although such literacy rates are unevenly distributed because some regions boast literacy rates of more than $90 \%$ and others fall below 40\% (Budhwar, 2001). Fourteen percent of the population takes advantage of the country's advanced educational system (Thorat, 2006). Despite these low overall literacy and higher education rates, given the population size of India, the country produces "the largest pool of scientific and technical personnel in the world" (Budhwar, 2001, p. 556).

The large population with its large pool of scientific and technical personnel has fueled GDP growth rates in India that have led the World Bank to forecast India as the fourth largest economy by 2020 (Budhwar, 2001). GDP growth rates over the past 10 years, however, have been unstable, dipping below 5\%, while also reaching above 9\% (Index Mundi, 2009). In addition to vacillating growth rates, India also suffers from limited participation from a large potential workforce pool that could contribute to more sustained growth in India's most lucrative sector: technology services. This potential drain on human capital may have negative implications for sustainable growth in this important and powerful industry sector (Pio, 2007). Within this context, therefore, the ability to develop the construct of hope as a means to grow human resources and improve performance should be of great importance to economic and business decision makers and leaders of multinational corporations.

India's population is linguistically and religiously diverse. For example, although the Indian constitution officially recognizes 16 languages, across the country, 179 languages are spoken, representing 544 dialects (Budhwar, 2001). The primary religious groups of Hindus, Muslims, Sikhs, Jains, and Buddhists (Budhwar, 2001) demonstrate India's religious diversity. Although English and Hindi are common languages, India is in 
the unique position of using English for nearly all business interactions (Pio, 2007; Singh, 1990). This English language factor, inclusive of a core of the scientifically and technically trained personnel, contributes to India's attractiveness in the global economy (Budhwar, 2001).

Context or cultural environment has a tremendous impact on individuals' attitudes, behaviors, and performance (Budhwar \& Sparrow, 2002;

The ability to build

willpower and

identify pathways,

as the hope

construct suggests,

may significantly

influence Indian

workers' ability

to move toward

performance

orientation and

to perform within

the contextual

climate described

by the preferred

values identified for

India's continued

robust economic

development.
Miller, 2003). Several studies have attempted to categorize cross-country differences according to specific dimensions (Hofstede, 1980; House \& Javidan, 2004; Trompenaars \& Hampden-Turner, 1998). Other studies have more definitively considered the historical, political, economic, religious, and social structures that influence attitudes and behaviors, which may affect performance (Chang \& Birtch, 2007; Chong, 2008; R. M. Peterson, Dibrell, \& Pett, 2002).

The GLOBE Study (Gupta, Surie, Javidan, \& Chhokar, 2002) of countries in the Southeast Asia cluster identified high group collectivism, power distance, and humane orientation as prominent societal practices. India mirrors these practices closely, although scoring slightly lower on humane orientation. These dimensions may explain the region's tendency to be group oriented and hierarchical. For example, in India, power distance may quickly be understood when one considers the stratification of the caste system and the country's long history of invasion and submission to outside powers (Gupta et al., 2002; Pio, 2007). While the dimensions of power distance, group collectivism, humane orientation, and gender egalitarianism describe the cur- rent practices of the Southeast Asian cluster, the GLOBE Study also identified values that represent managers' preferences for their countries' practices. In other words, the practices capture a snapshot of the culture "as is," whereas the values characterize projections of what "should be" (Gupta et al., 2002). High performance orientation, future orientation, group collectivism, humane orientation, and low power distance represent the value preferences for organizational practice. India closely mirrors the cluster, scoring slightly higher on performance orientation and lower on power distance, indicating that these values are becoming increasingly important for contemporary managers in India (Chang \& Birtch, 2007; Khandekar \& Sharma, 2006).

The desire to increase performance orientation and decrease power distance in the context of India's environment may be influenced positively by concerted efforts to develop high levels of hope (that is, attention to forming and implementing goals). The potential for hope to positively impact performance may play a significant role in sustaining the emergent BPO market in India (Youssef \& Luthans, 2007). More specifically, the ability to build willpower and identify pathways, as the hope construct suggests, may significantly influence Indian workers' ability to move toward performance orientation and to perform within the contextual climate described by the preferred values identified for India's continued robust economic development. Finally, hope may enable Indian managers to develop workers who will persist in overcoming constraints set by high power distance and low gender egalitarianism cultural dimensions.

\section{Theoretical Foundation and Study Hypotheses}

Hope is rooted in the positive psychology movement (Seligman, 1998, 2003; Seligman \& Csikszentmihalyi, 2000; Sheldon \& King, 2001; Snyder \& Lopez, 2002) and contributes to positive organizational behavior (POB) (Luthans, 2002a, 2002b, 2003). Positive psychology stresses optimal human functioning, focusing on positive psychological states that include hope (Snyder, 2000). Applying hope and other positive constructs to organiza- 
tions, Luthans (2002b) defined POB as "the study and application of positively oriented human resource strengths and psychological capacities that can be measured, developed, and effectively managed for performance improvement in today's workplace" (p. 59).

To be included in this conception of POB, constructs must meet the specific criteria of being positive, strengths-based, and unique to organizational behavior with strong theoretical and research support. Most importantly, the construct must be state-like and have the potential for development (Luthans, 2002a, 2002b, 2003). The hope construct meets these criteria. For example, hope (Luthans et al., 2005; S. J. Peterson \& Luthans, 2003) was found to be significantly and positively related to employees' performance outcomes in several contexts. For example, Luthans and Jensen (2002) found that entrepreneurs who scored high on hope had higher levels of ownership satisfaction. Similarly, Adams, Snyder, Rand, King, Sigmon, and Pulvers (2005) found that firm profitability, employee commitment, and satisfaction were related positively to levels of hope. Additionally, Luthans, Avey, Avolio, Norman, \& Combs (2006) demonstrated the malleability of hope to development. Specifically, hope is considered an important source of organizational competitive advantage and can be developed and managed to facilitate high impact work performance. The proposed relationship of hope to performance has critical importance for performance management, organizational sustainability, and employee development (Youssef \& Luthans, 2007).

\section{Hope as a Human Resource Capability}

Hope may have both long- and short-term impacts on performance. Increasingly, organizations have recognized that true and sustained competitive advantage results from effectively acquiring and developing human resources (Kossek \& Block, 2000). Human resources have been recognized to consist of both human capital and social capital. Human capital includes knowledge, skills, abilities, and experiences that individuals call upon to accomplish tasks (Dessler, 2000). Social capital re- fers to the individual's ability to navigate the interpersonal context of his or her environment (Adler \& Kwon, 2002). While these two components are necessary to our understanding of the antecedents of employee performance, they are not sufficient. In particular, they fall short of describing the complex cognitive processes that influence developing human capital or engaging social capital as mechanisms of performance impact. Going beyond human and social capital, hope focuses on critical cognitive processes that can either assist or impede employee capabilities to leverage talents to influence successful work performance (Luthans \& Jensen, 2002; Luthans \& Youssef, 2004). Moreover, the proposed developmental nature of hope provides organizations with an expanded repertoire to drive employee performance improvement and organizational profitability (Luthans et al., 2006). Thus, the hope construct and its potential impact on human capital assessment and development should be important to organizations seeking to optimize human resource management and human resource development.

\section{The Hope Capacity}

Two dimensions of hope, agency and pathways, describe how individuals identify and achieve goals. Snyder (2000) described agency as the motivation or willpower to work toward a goal. Agency encompasses the desire to develop goals and the commitment to work toward accomplishing goals. Pathways, or way power, refer to strategies for achieving goals. They represent the repertoire
Going beyond human

and social capital,

hope focuses on

critical cognitive

processes that can

either assist or

impede employee

capabilities to

leverage talents to

influence successful

work (Luthans

\& Jensen, 2002;

Luthans \& Youssef,

2004). Moreover,

the proposed

developmental nature

of hope provides

organizations with an

expanded repertoire

to drive employee

performance

improvement and

organizational

profitability (Luthans

et al., 2006). 
of strategies that can be identified to accomplish goals successfully. Those with high hope will have the ability to set appropriate goals and find alternative paths of action to obtain desired outcomes. Hope has been positively associated with academic

Worker attrition achievement (Snyder, Wiklund, \& Cheavens, 1999), athletic performance (Curry \& Snyder, 2000), preventing and recovering from physical illness (Irving, Snyder, \& Crowson, 1998; Snyder, Feldman, Taylor, Schroeder, \& Adams, 2000), coping with disability (Elliott, Witty, Herrick, \& Hoffman, 1991), and psychological adjustment (Snyder, Cheavens, \& Michael, 1999). More specific to this study, in a two-staged study of POB constructs, Youssef and Luthans (2007) found significant positive relationships between hope and employee performance, job satisfaction, and happiness. In spite of diverse applications of hope, few studies (S. J. Peterson \& Luthans, 2003; Youssef \& Luthans, 2007) have empirically examined the association of hope and workplace performance. Even fewer studies (Luthans et al., 2005; Luthans et al., 2008) have empirically investigated the relationship of hope to performance in non-Western settings.

As mentioned, hope has been explored in work settings regarding its potential impact on employee behaviors and organizational outcomes (Nelson \& Cooper, 2007; Sheldon \& King, 2001). In this study, we selected hope as the construct of interest for several reasons. First, the delineation of hope into two interacting components of cognitive strategies (agency and pathways) is associated with mechanisms by which individuals can interact with their environments by both inducing goal formation and generating alter- native strategies for accomplishing goals (Snyder, 2000). Second, while some positive constructs have been presented as being domain specific, hope can be leveraged across life and work domains (Luthans \& Jensen, 2002). Finally, in terms of cognitive and behavioral activation, individuals high in hope will tend to approach or move toward forming positive goals rather than focus on avoiding negative outcomes (Snyder, Tran, Schroeder, Pulvers, Adams, \& Laub, 2000). Indian BPO firms comprise a critical and major component of the country's current and future economic growth (Raman et al., 2007). As an emerging market, India's BPO organizations are experiencing high volatility and transition (Mody, 2004). Worker attrition and stress-related complaints have been widely demonstrated in Indian BPOs (Budhwar, Varma et al., 2006; Taylor \& Bain, 2005). We suggest that the goal-directed nature and strategy focus of hope are what Indian service workers may need to sustain current performance and promote effective coping in the volatile environment of emerging markets and the work structures of BPO organizations.

The state-like nature of hope suggests that individual responses of this variable are dynamic and changeable, thus making it amenable to development (Luthans \& Youssef, 2004; Snyder, Sympson, Ybasco, Borders, Babyak, \& Higgins, 1996). Also important to the utility of hope is its demonstrated application to workplace performance improvement. The psychology literature has demonstrated extensive positive and significant findings for hope (Kwon, 2000; Seligman \& Csikszentmihalyi, 2000; Snyder, 2000). This extensive work in clinical and positive psychology clearly demonstrates the progressive movement from debilitating personal behaviors to success in managing personal situations and life events. Work situations and events pose similar opportunities for human resource development (Combs \& Luthans, 2007; Combs, Luthans, \& Griffith, 2008) and performance management (Nadkarni \& Combs, 2006).

\section{The Relevance of Hope for the Indian BPO Sector}

We test our hypotheses for a small- to mediumsized enterprise (SME) from the BPO sector in In- 
dia. Offshore BPO involves transferring the operational ownership of one or more of a firm's processes to an external provider from another country, which then manages processes according to predetermined metrics (Kumar, Aquino, \& Anderson, 2007). The Indian BPO sector is characterized by factors that may both enhance and inhibit employee hope. On the one hand, the Indian BPO sector has been experiencing phenomenal growth rates, with a projected annual growth rate of $60 \%$ (Tapper, 2004). This high growth in the BPO sector provides lucrative opportunities for employees in terms of enhancing salaries, great perquisites such as transportation to and from work, and subsidized or free meals at work (Taylor \& Bain, 2005). Recent studies have suggested that the annual salary increases of Indian BPO employees ranged from 10 to 20 percent (Budhwar, Luthar et al., 2006). These lucrative opportunities are likely to enhance hope among Indian BPO employees by influencing the pathways component.

On the other hand, recent studies have highlighted the stress, racial and gender abuse, and other problems that considerably reduce $\mathrm{BPO}$ employees' morale (Budhwar, Luthar et al., 2006). The Indian BPO market consists of several types of organizations. These include captive firms, Indian third-party vendors, joint ventures, Indian IT software companies, global BPO players, and global consultancies (Budhwar, Luthar et al., 2006). The Indian BPO sector is dominated by captive firms, which cater their services to a single or a few clients (Taylor \& Bain, 2005). Client firms demand cost efficiency as well as customer service quality from such captive firms (Bain \& Taylor, 2000), which create a stressful environment for employees (Taylor \& Bain, 2005). Insufficient control, widespread workplace monitoring, creating difficult work targets, and the structure or lack of time away from the job (e.g., breaks and rest periods) create a pressurized and stressful environment for employees, which often results in negative workplace outcomes (Deery, Iverson, \& Walsh, 2002). Additionally, psychological stress and strain for BPO workers can be caused by tight and bounded work structures and work schedules (Hyman, Baldry, Scholarios, \& Bunzel, 2003) and the need for workers to adopt the customer accents of one or more specific clients (Taylor \& Bain, 2005). This has created high attrition rates among Indian employees. For example, Budhwar, Luthar et al. (2006) reported that annual turnover rates in the Indian BPO firms ranged from 20 percent to 80 percent. This high attrition rate further creates work disruptions and difficulties for remaining employees. Together, these factors are likely to inhibit hope among employees.

Worker job satisfaction, commitment, absenteeism, attrition, and burnout are tremendous performance and productivity issues for BPO firms. Understanding the levels of hope among BPO employees and taking efforts to improve these levels can help Indian BPO firms improve employee work satisfaction and productivity and help reduce attrition and worker burnout. Several studies have associated hope with workplace issues that impact worker performance. For example, Locke (1976) suggested that job satisfaction was a function of appraising current work and work-related conditions. Job satisfaction is related to but distinguishable from hope because hope involves assessing expected future positive feelings over future negatives (Staats \& Stassen, 1985). Snyder (2000) indicated hope was focused on $\mathrm{fu}$ ture positive events based on the cognitive identification of pathways toward positive outcomes.

Similarly, the levels of stress Indian BPO workers experience and the ability of workers to handle the stress and frustration of the BPO work environment (Budhwar, Varma et al., 2006) may be affected by their levels of hope. Snyder (2000) found that those with hope in stressful professions perform better and exhibit higher levels of satisfaction and less emotional exhaustion and are more likely to stay. A more recent study that focused on the role of hope and job performance in a sample of 1,032 workers found that hope was related to job satisfaction, work happiness, commitment, and performance (Youssef \& Luthans, 2007). 
Indian BPO firms are plagued with high levels of employee attrition within the context of bureaucratic and tightly controlled work environments (Budhwar, Varma et al., 2006; Taylor \& Bain, 2005). Hope, through its link to job satisfaction and commitment, may also influence turnover intentions (empirical proxy for turnover) and absenteeism demonstrated by Indian BPO workers. Tett and Meyer (1993) found that job satisfaction was a strong predictor of intention to quit. Lum, Kervin, Clark, Reid, and Sirola (1998) found that job satisfaction had an indirect relationship on intention to quit, whereas commitment had a direct effect on intention to quit. Based on the hope-satisfaction link and research linking satisfaction to turnover intentions, it may follow that Indian BPO workers who are more hopeful will have more job satisfaction and demonstrate less interest in leaving the organization. Although research on hope and absenteeism is limited, one study conducted by Avey, Patera, and West (2006) found that hope shared a significant negative relationship with voluntary and involuntary absenteeism. This parallels research conducted by Judge (1993), which found job satisfaction and turnover were strongly and negatively related for individuals with high positive affect.

Although Indian BPO firms tend to have systematic and routine performance appraisal programs, scholars have recognized worker participation in performance management is lacking (Budhwar, Luthar et al., 2006). For example, Budhwar, Luthar et al. (2006) report the Indian BPO environment for performance management is one that "exhibits little participation of individual employees regarding their goal setting" (p. 353). The numerous studies on goal setting have clearly demonstrated the link between forming goals and positive employee performance (e.g., Lee, Locke, \& Latham, 1989; Locke \& Latham, 1990). Implementing the hope processes of goal setting (pathways) and its associated focus on strategies for accomplishing goals (agency) could be beneficial in addressing this issue. Hope requires direct involvement of workers in thinking critically about work processes and responsibilities. Additionally, employees would identify strategies and obstacles to accomplish goals. The agency and pathways concepts of hope may encourage more Indian BPO employee participation and engagement in setting individual and group performance goals, thereby positively influencing employee and organizational performance.

Given the research on the theoretical foundation of hope, the context of Indian BPO service workers, and the association of hope with performance outcomes, we hypothesize that:

Hypothesis 1: Hope of Indian BPO workers will have a positive relationship with performance as measured through direct merit-based salary (commission).

\section{Hypothesis 2: Hope of Indian BPO workers will have a positive relationship with performance as measured through supervisor rating.}

\section{Study Methods}

Data were collected from a sample of 160 employees from a privately held Indian information technology services firm. The dependent variables (performance measures) were obtained through merit-based commission and supervisor ratings of employee performance. Such performance-based compensation is widely recognized as a measure of performance (Dessler, 2000). Commission plans directly dictate final compensation amounts as a result of objective measurement of concrete individual efforts toward preestablished performance goals. In addition to commission, performance can also be measured based on supervisory ratings. For this study, participants' supervisors rated employee performance based on a standard questionnaire provided by the researchers.

\section{Study Site and Sample}

We tested our hypotheses in a 500-employee BPO firm in Mumbai, which provided a range of back-office and customer support services such as back-office accounting, payroll, HR, and call centers as well as IT support. This firm represented a 
"captive" structure (Taylor \& Bain, 2005) typical of most SMEs in Mumbai. Accordingly, this firm provided exclusive services to two large multinational companies - one in the telecommunications sector and another in the banking and finance sector.

The company has a matrix structure where employees from different functional areas are assigned to work in teams based on project needs. A hierarchy of positions exists, however, that is composed of six levels. The first level, Telesales and Data Entry, accounted for 34 percent of the sample, followed by Software Analysts, who made up 32 percent. Team Leaders, the next level, represented 17 percent of the sample; Project Leaders accounted for 12 percent of the sample; Senior Managers made up 4 percent; and 2 percent of the sample were Top Managers. Women compose 29 percent of the sample.

\section{Procedure}

Data collection proceeded through a series of steps. First, we contacted the Human Resource administrator and members of the top management team to explain the purpose of our study and to request permission to administer the survey. Second, the Human Resource administrator sent an e-mail to employees introducing the study and encouraging voluntary participation. Third, the Human Resource administrator distributed copies of the survey to employees. Employees were given one week to complete the survey and were instructed to seal the envelope and return it to the researchers. One of the researchers physically collected the sealed envelopes from employees. Fourth, the Human Resource administrator sent a reminder to non-respondents and gave them an additional week to complete the survey. The late responses were also collected physically from the respondents. We found no significant differences in variables between early and late responders. The final sample consisted of 160 employees (32 percent response rate).

The survey questionnaire contained the widely used and standardized hope scale (Snyder, 2000). Completed confidential questionnaires were returned to the researchers and assigned a code so that responses could be matched with each participant's performance data. Because of the respondents' English proficiency and the use of English as the business language of this organization, translation of the survey questionnaire was not needed. The questionnaire was successfully pilot tested, however, with a sample of the organization's employees to ensure understanding and interpretation of the questionnaire items.

Performance data were obtained from the first available assessment and calculations of commission. Supervisor ratings of participants were obtained through a short questionnaire that was returned to the researchers at about the time that participants completed the hope measure.

\section{Measures}

Hope

Snyder and colleagues developed a reliable and valid instrument to measure hope (Snyder, 2000). This instrument captured the two theoretical components of pathways and agency. For example, "I meet the goals I set for myself" represents agency, whereas "I can think of many ways to get out of a jam" is an indicator of pathways. With 12 items measured on a Likert scale, this self-report instrument has replicated reliably in many environments. Responses for the 12 items range from $1=$ "Definitely False" to $8=$ "Definitely True." Cronbach's alpha for this study was $\alpha=.96$.

\section{Commission}

Commission is a direct measure of performance tied to a tangible unit for each employee and calculated as a variable percentage of total units specific to each job category. For example, unit sales up to 20,000 units have a 10 percent commission, and 20,000 to 100,000 units receive 15 percent, and so on. For support employees, commission is based on different levels of service requests completed or client problems solved. For all workers, the aggregate commission is the weighted average at different levels of performance. 


\section{Supervisor Ratings}

Performance based on supervisor ratings was obtained through a questionnaire provided by the researchers. This six-item survey rated aspects of performance such as work quality, work commitment, and work efficiency on a scale of 1 to 10 . For example, items included "Please rate the employee's overall quality of work accomplished" and "Please rate the employee's overall work efficiency." The direct supervisor of each participant in the study completed this questionnaire. The Cronbach's alpha for the supervisor ratings measure was $\alpha=.91$.

\section{Analyses and Study Results}

Data analysis was conducted using Pearson correlation, step-wise hierarchical linear regression, and structural equation modeling (SEM). Step-wise hierarchical linear regression allows the comparison of nested models to understand the change in model fit. It was prudent to first test the independent relationships of hope with the two dependant variables prior to testing overall model fit, with hope predicting both dependent variables (Nunnally \& Bernstein, 1994), as is presented here with the structural equation model evaluation.

Table I shows the descriptive statistics and the correlations for the study variables. The mean score for hope on an 8-point scale was 6.70 (S.D. = 1.29). The hope scores of Indian BPO service workers are comparable or slightly higher than that found in Luthans et al.'s (2005) study of Chinese factory workers.

As shown in Table I, there is support for Hypothesis 1 : hope $(r=0.52, p<0.01)$ showed a positive and highly significant relationship with performance as measured by commission. Commission is the most direct measure of performance; therefore, these results provide strong support for the relationship of these Indian BPO workers' hope and their performance. Examining hope via supervisor performance ratings, per Hypothesis 2, also showed a positive and significant relationship $(r=0.20, p<0.01)$. Hypotheses 1 and 2 are thus supported.

To investigate the contribution of hope to performance together with gender and work experience, step-wise regression analyses for commission and supervisor ratings were conducted. Given the gender differentials in India (Gupta et al., 2002) and the potential effect of gender on hopeful attitudes, controlling for this variable seemed logical. The duration and type of experiences acquired in the workplace significantly influence work expectations and how an employee interprets events occurring in a work environment. We also controlled, therefore, for work experience. Importantly, as reported in Table I, social desirability did not have a significant relationship with any of the self-report items; therefore, it was not included in the stepwise regression analysis.

Gender and work experience were entered first into the regression equation. Tables II and III show the results of these analyses. As seen in Table II for

Table I. Inter-Correlations Among Study Variables

\begin{tabular}{lrrrrrrr}
\hline & M & SD & I & 2 & 3 & 4 & 5 \\
\hline I. Social desirability & 0.54 & 0.14 & & & & & \\
2. Work experience & 33.76 & 32.76 & 0.03 & & & & \\
3. Gender & & & 0.07 & $.33^{* *}$ & & & \\
4. Hope (8-point scale, I-8) & 6.70 & 1.29 & 0.04 & 0.14 & $0.33^{* *}$ & & \\
5. Supervisor-rated performance & 5.61 & 1.65 & & -0.08 & 0.06 & $0.20^{* *}$ & $0.44^{* *}$ \\
6. Commission & 0.16 & 0.05 & & -0.01 & 0.13 & $0.52^{* *}$ &
\end{tabular}

$N=160$.

* Significant at 0.05 level (two-tailed).

** Significant at 0.01 level (two-tailed). 
commission, the F-test was not significant. This established that gender and work experience alone were not predictive of performance as measured most objectively by commission. Table III shows supervisor ratings also had a non-significant F-statistic with gender and work experience as predictors.

Controlling for gender and work experience variables, the second step in the regression analyses was to enter hope. For commission, the $R^{2}=.28$ $(p<.0001)$ and for supervisor rating $R^{2}=.05(p<$ $.01)$. The $R^{2}$ change was significant for both measures of performance, showing .26 $(p<.0001)$ and $.03(p<.05)$ for commission and supervisor ratings, respectively. Because hope made a much larger contribution to commission than to supervisors' ratings, there is evidence that agency and path- ways of hope play a large role in achieving performance objectives for which an employee is directly rewarded (merit-based pay). In the case of supervisor ratings, in which the beta weight of hope was comparatively smaller than with commission, it may be that other important $\mathrm{POB}$ constructs also contribute to performance reviews.

Post hoc analysis was conducted using a structural equation modeling (SEM) method with the MPlus software program. Figure 1 reflects the model tested. The items to measure this latent variable were set to predict both variables of performance. When evaluating the fit of a structural model, scholars have suggested using a combination of the chi-square, comparative fit index (CFI), the root mean square error of approxima-

Table II. Step-wise Regression for Commission

\begin{tabular}{lccccc}
\hline & \multicolumn{2}{c}{ Step I } & & \multicolumn{2}{c}{ Step 2 } \\
\cline { 2 - 3 } \cline { 5 - 6 } & Beta & $t$ & & Beta & $t$ \\
\hline Work experience & -0.05 & -0.6 & -0.07 & -0.975 \\
Gender & -0.13 & -1.59 & & 0.28 & 0.37 \\
Hope & & & 0.54 & $7.463^{* *}$ \\
Change $R^{2}$ & & & $0.26^{* *}$ & \\
Overall $R^{2}$ & 0.02 & & & 0.28 & \\
Overall F & 1.26 & & \multicolumn{2}{c}{$19.70^{* *}$} \\
\hline
\end{tabular}

$N=160$

$* * p<.01$ (two-tailed)

Table III. Step-wise Regression for Supervisor Ratings

\begin{tabular}{|c|c|c|c|c|}
\hline & \multicolumn{2}{|c|}{ Step I } & \multicolumn{2}{|c|}{ Step 2} \\
\hline & Beta & $t$ & Beta & $t$ \\
\hline Work experience & -0.11 & -1.35 & -0.12 & -1.45 \\
\hline Gender & -0.09 & -1.1 & -0.03 & -0.39 \\
\hline Hope & & & 0.2 & $2.4 I^{*}$ \\
\hline Change $R^{2}$ & & & $0.03^{*}$ & \\
\hline Overall $R^{2}$ & 0.02 & & 0.05 & \\
\hline Overall F & 1.15 & & $2.73 I^{*}$ & \\
\hline
\end{tabular}

$N=160$

$* p<.05$ (two-tailed)

$* * p<.0$ l (two-tailed) 


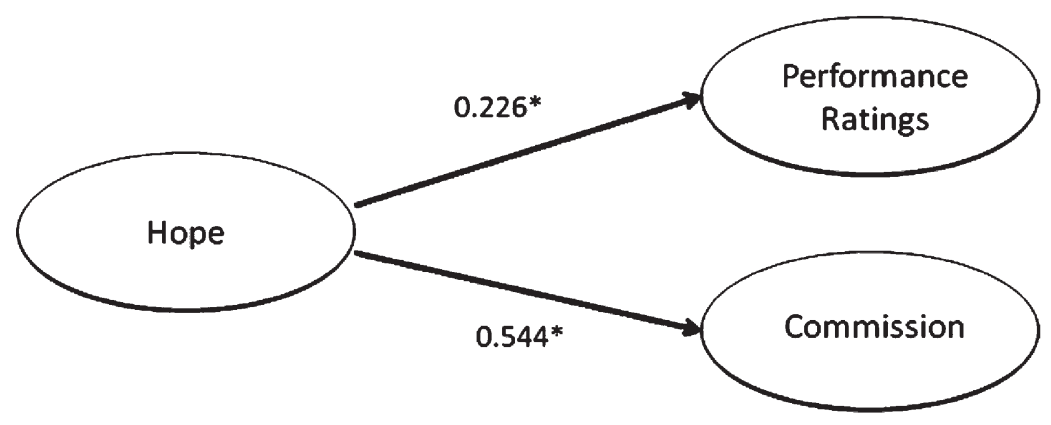

Figure I. Hypothesized model with structural equation path weights

tion (RMSEA), and the standardized root mean residual (SRMR) (Bentler, 1990; Hu \& Bentler, 1999). As shown in Table IV, the chi-square statistic was 205.487 (degrees of freedom $=88$ ); the CFI was 0.946 (acceptable cutoff: 0.90); RMSEA was 0.092 (acceptable cutoff for very good fit: 0.06); and the SRMR was 0.037 (acceptable cutoff: 0.08). Specifically, the CFI and SRMR both indicate an acceptable fit, per Hu and Bentler's (1999) guidelines. The RMSEA does not fall within the general level of acceptable fit; however, $\mathrm{Hu}$ and Bentler (1999) argued that acceptable indices in two of these three fit indicators provide evidence of a reasonable fit of the overall model. The paths of the relationship to the two performance variables were statistically significant with betas of $0.226(p<.01)$ with performance ratings and $0.544(p<.001)$ with commission, which is consistent with the step-wise regression results.

\section{Discussion}

The purpose of this study was to demonstrate the relevance of hope to performance outcomes for Indian service workers in the BPO industry. We found that hope related positively to employees' supervisory performance ratings and perfor- mance-based commission that employees earned. These results provide major theoretical contributions to research on hope as well as research on the BPO industry.

A major theoretical contribution of this study is the generalizability of findings to the Indian culture. Recent studies have called for examining the cross-cultural relevance of major psychological constructs (Luthans et al., 2005). In this study, we tested whether the positive organizational behavior (POB) construct of hope influences performance in cultures (India) other than the U.S. and China. This study extends the findings of Luthans et al.'s (2005) study of Chinese factory workers by testing the relationship not only in a new cultural context, but also in an industry in which these relationships have not yet been tested. Moreover, this study's positive relationship of hope to performance in a sample of Indian BPO service workers extends the potential application of positive organizational behavior to more than low technology, manufacturing environments. Examining relationships of constructs across cultures not only validates these constructs, but also improves our theoretical understanding of these constructs. Again, we found that in the non-Western cultural context of India, hope was positively and significantly re-

Table IV. Structural Equation Modeling Fit Indices

Fit Value

\begin{tabular}{lc}
\hline Chi-square & $205.487(\mathrm{Df}=88)$ \\
CFI & 0.946 \\
RMSEA & 0.092 \\
SRMR & 0.037
\end{tabular}


lated to two commonly used measures of employee performance, commission and supervisor ratings. The application of hope in non-Western cultures (China and now India) offers incentives to further test positive organizational behavior constructs in cross-cultural settings.

Another theoretical contribution, especially for the BPO industry, is to link hope to non-productive aspects of organizational environments. The counter-productive challenges (Hyman et al., 2003) workers faced may influence lesser levels of performance. From this study, we might infer relationships between counter-productive factors (e.g., burnout) and components of the hope construct. Although the study did not directly examine the relationship between hope and these counter-productive elements of the Indian BPO work environment, there may be potential connections among hope, the ability to manage counter-productive work situations, and performance. Additionally, workers from the Indian BPO industry must interact with people from different cultures. Understanding how hope might influence the behaviors of people from different cultures can help these firms develop practices that can improve customer support and organizational competitive advantage.

This study was conducted in the context of Indian workers in the BPO global markets. The social and political conditions of India and the working conditions $\mathrm{BPO}$ workers experience give rise to examining the methods and mechanisms that may enhance individual and organizational performance. Performance issues are seriously impacted by overarching characteristics of the work environment including high levels of attrition, low job satisfaction and commitment, a high degree of worker burnout, and concerns for effective work-life balance (Hyman et al., 2003; Taylor \& Bain, 2005). In this study, hope is shown to be highly related to performance as measured by commission and supervisor ratings. In essence, for workers higher levels of hope are associated with higher performance. Thus, the issues negatively affecting performance in the BPO settings may be reduced or alleviated by increasing workers' hope.
The agency (goal formation) and pathways (identifying strategies for accomplishing goals) components of hope may allow Indian BPO workers to generate goals to circumvent the more negative aspects of their work environment. Additionally, workers will be able to anticipate and prepare for obstacles by assessing alternative paths. This process will permit workers to not become stymied by, or stuck in, a particular response mode to obstacles. Such obstacles could be factors such as rigidity in work schedules and bounded work structures. High-hope BPO workers can envision attaining goals even when faced with goal blocks that could impede performance. We suggest that high-hope Indian BPO workers can develop goals and goal-attainment strategies that may allow them to engage or act on the work environment to increase their job satisfaction, reduce attrition, and reduce job-related stress.

Indian BPO workers characterize their work environment as one of excessive pressure and lack of control. Hope may stimulate perceptions of, or provide actual control of, work outcomes. Feelings of increased psychological control may reduce pressure associated with tight performance targets. Perceived lack of control of work and family life due to highly scripted and prescribed work behaviors and long and egregious extensions of work hours (Hyman et al., 2003) may be positively influenced through the pathways component of hope. Additionally, setting realistic goals and assessing strategies for attaining those goals may result in opportunities for enhanced employee voice in work design, including more worker input into how Indian BPO employees might more effectively perform their jobs. Luthans et al. (2006) demonstrated, through highly focused micro-interventions, the capacity to develop agentic and pathways thinking. The length 
of the micro-interventions would align with short BPO training cycles. For example, Combs et al. (2008) suggested that the microintervention model could be applied to the prior training, regular skill training, and competency- based training to increase employee motivation to engage in training. Applying the micro-intervention may increase learning during training and enhance the transfer of training. This type of intervention strategy could give workers effective coping mechanisms to handle the negative elements of their work environments.

From a country culture perspective, as the world's second most populous country, India has the human capital and resources to achieve sustainable growth and emerge as an important contributor to the global economy (Khandekar \& Sharma, 2006; Pio, 2007). Several obstacles, however, potentially stand in the way of India's sustainable global competitiveness. Issues such as wide dispersion in literacy rates and being among the lowest ranked countries on the Human Development Index may provide formidable challenges for the economy's ability to forge ahead (Pio, 2007). Furthermore, as the GLOBE Study (Gupta et al., 2002) reported, cultural practices may be incongruent with desired cultural values, pointing out India's need to develop human capacity.

From a national perspective (e.g., GDP growth rates), the benefit of hope might be found in the plight and circumstances of nonurban and castespecific citizens who must compete for educational and economic opportunities under unfavorable odds (Budhwar \& Sparrow, 2002). Recognizing and developing hope for these marginalized groups could increase the probability and reality of higher education, thereby allowing India to sustain its global competitive advantage in engineering and technology innovation. Particularly telling in this study was the strong relationship of hope with the most objective measure of performance: commission. Such outcomes indicate that individuals can control their performance and approach to job tasks. By developing personal resources of hope (agency and pathways), individuals may accelerate their performance and thereby improve their personal, so- cial, and economic situations. Furthermore, hope can be developed in human resource practices to enhance worker productivity and bridge current and future human resource capital requirements for Indian service workers (Khandekar \& Sharma, 2006).

On an organizational level, BPO and other multinational organizations that either staff facilities or enter alliances with other firms would do well to examine the utility of hope for acquiring, integrating, and developing their human resources. Strategic human resource practices must not only examine the impact of performance factors on organizational profitability (Budhwar, Luthar et al., 2006; Dessler, 2000), but also seek to determine how positive performance influences are created (Wright, Gardner, \& Moynihan, 2003). Hope could be used in the recruiting and selecting processes for Indian BPO firms to identify applicants who are highly motivated toward forming and attaining goals. Hope might also establish alternative pathways and strategies for attaining goals and have direct and positive approaches for adjusting to the pressures and psychological stressors of the $\mathrm{BPO}$ work environment.

For global organizations, strengths in hope could positively influence adjustment to novel situations and diverse work groups. Geocentric human resource models are important elements of global organizations (Evan et al., 2002). Yet a unique mix of different cultures and perspectives can infuse conflict and ambiguity into the work setting (McGowan, 2004). Indian BPO workers are required to adjust to the client organization's customer base and often must mimic the accent of the client's customers (Taylor \& Bain, 2005). This can result in ineffective emotional interactions and debilitating emotional labor for employees (Hyman et al., 2003). As Indian workers begin to interface with different cultures and integrate Indian and other cultural perspectives, individual propensity for hope may help ameliorate potential problems and positively influence performance outcomes (Nelson \& Cooper, 2007).

In general, this study's findings contribute to the complexity of understanding human nature and the factors that drive performance. Given this com- 
plex world, however, it is important to note that hope may illuminate individual differences in patterns of employee development and outcomes ( $\mathrm{Lu}-$ thans \& Jensen, 2002). The results of hope across two measures of performance make a strong case for its consideration in developmental activities directed toward improving performance and increasing productivity in general and toward Indian $\mathrm{BPO}$ workers in particular.

\section{Practical Implications}

The positive relationship of hope with employee performance suggests that hope is a valuable psychological resource that can be used to develop effective HRM practices. There are several implications of this study for HRM practices in Indian BPO firms; below we present several applications.

Managing and developing human capital appear to be at the center of emerging problems in the Indian BPO sector (Budhwar, Luthar et al., 2006; Sparrow \& Budhwar, 1997). Human resource development (HRD) seems to be the preferred perspective over human resource management. Given this HRD focus, Sparrow and Budhwar (1997) suggested that a developmental model for improving human capital would fit well in addressing career and human capital issues in the Indian BPO workforce. The authors refer to the Indian conceptualization of HRD/HRM as being metaphysical with a focus on general assumptions about people; for example, the individual as a free being and the individual's urge for self-fulfillment and growth potential (Sparrow \& Budhwar, 1997). From an overall HRD/ HRM strategy perspective, hope could enhance both employee skill development and organizational competitiveness through its focus on forming short- or long-term goals. For example, career development requires the ability to identify aspirations, career-related objectives, and methods/mechanisms to ensure career objectives are attained successfully (Gomez-Mejia, Balkin, \& Cardy, 2009). Similarly, growth potential can be enhanced through recognizing and discovering alternative pathways and configurations for accentuating individual growth. The hope construct focuses on the individual and his or her ability to envision and enact his or her own success. In this regard, Indian BPO managers can use hope as a tool to enhance workforce creativity and to positively influence organizational innovation.

Bonuses and other forms of compensation are associated, in part, with worker performance and skills. Budhwar, Luthar et al. (2006) reported the use of individualized bonuses for junior-level managers. Individuals at this level work most closely with employees and have a great impact on the drivers of success for Indian BPOs. Implementing hope has the potential to assist junior-level managers in identifying work goals that can directly influence the work of employees who have direct contact with customers and clients. Not only can hope provide a basis for formulating strategy for junior-level managers, but junior-level managers may also transfer acquired skills in goal setting and formulating strategy to the employees they manage.

Developing and measuring interventions to boost levels of hope in employees may help Indian BPO firms combat psychological problems such as employee stress and burnout. Improving levels of hope may also help reduce the employee attrition that has plagued the Indian BPO industry. Improvements The results of hope across two measures of

performance make a strong case for its consideration in developmental activities directed toward improving performance and increasing productivity in general and toward Indian BPO workers

in particular. in these problem areas should considerably improve client satisfaction, reduce work disruptions, and improve firm performance. The developmental nature of hope affords the opportunity to establish and implement micro-interventions to focus on enhancing these positive strengths (Combs et al., 2008; Luthans et al., 2006). This type of intervention may improve the human resource capacities of BPO firms to create, innovate, and sustain competitive advantage across cultural environments where differences in societal 
norms and organizational practices can severely influence individual job performance. For example, as Indian BPO employees interact with client customers from different cultures with the associated plurality of customer service expectations, having the opportunity to develop and explore alternative strategies to meet customer needs may reduce or eliminate worker burnout and psychological stress that can influence attrition. Additionally, the ability to balance work/life issues effectively could benefit from this type of strategy-building process, which, in turn, could positively influence worker productivity and job satisfaction.

The culture, belief systems,
Developing

and measuring

interventions to

boost levels of

hope in employees

may help Indian

BPO firms combat

psychological

problems such as

employee stress and

burnout. values, and norms operating in a society have a considerable impact on the operationalization of HRM practices (Budhwar \& Sparrow, 2002). The normative structure of national culture can also influence employee attitudes and behaviors about work and work-related processes (Sparrow \& Budhwar, 1997). For example, Sparrow and Budhwar (1997) conducted a comparative analysis of HRM practices in 13 countries including India. In examining nine specific HRM factors, they revealed low scores for India on structural empowerment (e.g., high performance work systems), accelerated resource development (e.g., establishing multiple/ parallel career paths, rewards for enhancing skills), and efficiency emphasis (e.g., specification of organizational directives, employee selfmonitoring and adjustment). Components of the Indian culture, and therefore the Indian BPO organizational culture, reflect the low measure of these three HRM factors. What might be needed to improve these three HRM processes are more empowered workers who have the ability to selfmonitor and who possess a desire and ability to enhance skills and career aspirations. Employees would need to engage in self-examination and self-regulate behaviors. The agentic nature of the hope construct could prepare Indian BPO workers to engage in more participative styles and to monitor their personal career growth needs. A more systematic movement to these types of HRM process through training and developmental interventions to build employee hope may mediate the Indian BPO problems with attrition and workplace stress, which potentially impede worker productivity. Additionally, the practice in India of giving over HRM functions to line managers (devolvement) (Budhwar \& Sparrow, 2002) makes a more empowered workforce even more necessary.

\section{Limitations and Conclusions}

This was not an experimental study; therefore, no causal interpretations can be made about the effect of hope on workplace performance. The strong correlations and multiple regression results, however, provide at least preliminary evidence of significant performance impact.

The two measures of performance provided strength to the study. The more direct and objective commission measure of performance was effective in identifying individual performance, and the results indicated a very strong relationship. Supervisor ratings were also significantly related to hope. Although the performance measure of supervisor rating was moderate and not so strong as commission, the measure was found to be reliable. This provides evidence that supervisors might rate performance based on behaviors other than those that directly impact tangible outcomes. While hope likely influences these behaviors, it has a much stronger orientation toward the behaviors that directly create a path to the desired goal.

We hypothesized direct effects of hope on performance. Given the different forms of performance measured and the most powerful results stemming from objective measures of performance (commission), however, a future research question may be to examine what, if any, intervening processes influence performance. For example, to what degree is hope associated with self-regulating behaviors that may mediate these effects on perfor- 
mance, particularly objective performance, either partially or fully?

Through the relationship of hope to performance, this study directly supports positive organizational behavior (Luthans, 2002a, 2002b, 2003) and indirectly psychological capital (Luthans et al., 2006; Luthans \& Youssef, 2004). Hope has been found to be developmental in nature (Luthans et al., 2006). Therefore, an important implication of this study is that hope might be strengthened within individuals and provide a mechanism for Indian BPO organizations to significantly reduce work environment stress, employee attrition, and burnout (Budhwar, Varma et al., 2006), thereby enhancing employee and organizational performance. Snyder (2000) has contributed to the guidelines for building hope. More recently, Luthans et al. (2006) provided more details for specific micro-interventions for developing hope and other BPO constructs.
This study demonstrates the positive and significant relationship between hope and two common yet different measures of work performance in an Indian services firm that fits the context of the Indian BPO market segment. Using such a segment of Indian service workers adds to the generalizability of hope to performance across cultures and industries. The results indicate that high-impact performance in Indian BPOs and potentially other emerging markets might be influenced by developing human resource psychological capacities for forming goals, formulating strategy for implementing goals, and identifying alternatives or contingencies for accomplishing goals. Developing and leveraging hope in Indian BPO workers, therefore, may be a sustainable method for increasing performance. Emphasizing and developing the hope construct may increase economic and personal growth in the Indian BPO markets and find applicability across different cultural work environments.

Gwendolyn M. Combs is an associate professor of management at the University of NebraskaLincoln, Lincoln, Nebraska. She received her Ph.D. from the University of Nebraska-Lincoln. Her research interests include human resource management and organizational behavior. Her research examines the impact of diversity and group identity on inter-group behavior and performance, and the influence of positive organizational constructs on employee attitudes, talent sourcing, and performance. Dr. Combs has published in the Journal of Organizational Behavior, Human Resource Development Quarterly, Journal of World Business, Journal of Leadership Studies, Howard Law Journal, Human Resource Development Review, and Organizational Dynamics.

Rachel Clapp-Smith is an assistant professor of leadership at Purdue University Calumet. She received her Ph.D. from the University of Nebraska. Dr. Clapp-Smith has published in journals such as the Journal of Leadership and Organizational Studies, Journal of Business and Leadership, and International Journal of Human Resource Management, as well as peer-reviewed volumes such as Global Mindset:Advances in International Management. Dr. Clapp-Smith has also presented at a number of conferences including the Academy of Management. Her research interests are global mind-set and global leadership development, as well as international aspects of organizational behavior.

Sucheta Nadkarni is an associate professor in the LeBow College of Business at Drexel University, Philadelphia, Pennsylvania. She received her Ph.D. from the University of Kansas. Her research interests are in the areas of strategic cognition and human resource management. Dr. Nadkarni has published or has forthcoming papers in journals such as Academy of Management Journal, Strategic Management Journal, Organization Science, Journal of International Business Studies, Organizational Research Methods, MIS Quarterly, and Journal of World Business. 


\section{References}

Adams, V. H., Snyder, C. R., Rand, K. L., King, E.A., Sigmon, D. R., \& Pulvers, K. M. (2005). Hope in the workplace. In R.A. Giacolone \& C. S. Jurkiewicz (Eds.), Handbook of workplace spirituality and organizational performance (pp. 345-366). New York: Sharp.

Adler, P., \& Kwon, S. (2002). Social capital: Prospects for a new concept. Academy of Management Review, 27( I), 17-40.

Avey, J. B., Patera, J. L., \& West, B. J. (2006). Positive psychological capital:A new approach for understanding absenteeism. Journal of Leadership and Organizational Studies, I3(2), 42-60.

Bain, P., \& Taylor, P. (2000). Entrapped by the "electronic panopticon"? Worker resistance in call centres. New Technology, Work and Employment, I5(I), 2-I8.

Bentler, P. M. (1990). Comparative fit indexes in structural models. Psychological Bulletin, I07(12), 238-246.

Budhwar, P. (200I). Doing business in India. Thunderbird International Business Review, 43(4), 549-568.

Budhwar, P. S., Luthar, H., \& Bhatnagar, J. (2006). Dynamics of HRM systems in BPOs operating in India. Journal of Labor Research, 27(3), 339-360.

Budhwar, P. S., \& Sparrow, P. R. (2002). Strategic HRM through the cultural looking glass: Mapping cognitions of British and Indian HRM managers. Organization Studies, 23(4), 599-638.

Budhwar, P. S., Varma, A., Singh,V., \& Dhar, R. (2006). HRM systems of Indian call centres:An exploratory study. International Journal of Human Resource Management, I7(5), $881-897$.

Chang, F. F.T., \& Birtch, T.A. (2007). Examining the perceived causes of successful employee performance:An east-west comparison. International Journal of Human Resource Management, I8(2), 232-248.

Chong, E. (2008). Managerial competency appraisal:A crosscultural study of American and East Asian managers. Journal of Business Research, 6I(3), 191-200.

CIA World Factbook. (2009). Retrieved August 3I, 2009, from https://www.cia.gov/library/publications/ the-world-factbook/geos/in.html

Combs, G. M., \& Luthans, F. (2007). Diversity training:Analysis of the impact of self-efficacy. Human Resource Development Quarterly, I6(I), 91-I20.

Combs, G. M., Luthans, F., \& Griffith, J. (2008). Learning motivation and transfer of human capital development: Im- plications from psychological capital. In C. L. Cooper \& R. Burke (Eds.), The peak performing organization (Pp. 7391). New York: Routledge.

Curry, L., \& Snyder, C. R. (2000). Hope takes the field: Mind matters in athletic performances. In C. R. Snyder (Ed.), Handbook of hope:Theory, measures and applications (Pp. 243-260). San Diego, CA:Academic Press.

Deery, S., Iverson, R., \& Walsh, J. (2002). Work relationships in telephone call centres: Understanding emotional exhaustion and employee withdrawal. Journal of Management Studies, 39(4), 47I-496.

Dessler, G. (2000). Human resource management. Upper Saddle River, NJ: Prentice Hall.

Elliott, T. R., Witty, T. E., Herrick, S., \& Hoffman, J.T. (I99I). Negotiating reality after physical loss: Hope, depression, and disability. Journal of Personality and Social Psychology, 6I, 608-613.

Emerging-market indicators. (2005, December 3). Economist, $377,98$.

Evan, P., Pucik, V., \& Barsoux, J. (2002). The global challenge: Frameworks for international human resource management. New York: McGraw-Hill/Irwin.

Gomez-Mejia, L., Balkin, D., \& Cardy, R. (2009). Managing human resources. Upper Saddle River, NJ: Prentice Hall.

Gupta,V., Surie, G., Javidan, M., \& Chhokar, J. (2002). Southern Asia cluster:Where the old meets the new? Journal of World Business, 37(I), 16-27.

Hofstede, G. (1980). Culture's consequences. Beverly Hills, CA: Sage.

House, R. J., \& Javidan, M. (2004). Overview of GLOBE. In R. J. House, P. J. Hanges, M. Javidan, P.W. Dorfman, \& V. Gupta (Eds.), Culture, leadership, and organizations:The GLOBE study of 62 societies (pp. 9-280). Thousand Oaks, CA: Sage.

Hu, L., \& Bentler, P. M. (1999). Cutoff criteria for fit indices in covariance structure analysis: Conventional criteria versus new alternatives. Structural Equation Modeling, 6I (I), $1-55$.

Hyman, J., Baldry, C., Scholarios, D., \& Bunzel, D. (2003).Worklife imbalance in call centres and software development. British Journal of Industrial Relations, 4 I (2), 2I 5-239.

Index Mundi. (2009). Retrieved August 31, 2009, from http:// www.indexmundi.com/india/gdp_real_growth_rate.html

Irving, L. M., Snyder, C. R., \& Crowson, J. J., Jr. (1998). Hope and the negotiation of cancer facts by college women. Journal of Personality, 66, 195-214. 
Judge,T.A. (1993). Does affective disposition moderate the relationship between job satisfaction and voluntary turnover? Journal of Applied Psychology, 78(3), 395-40I.

Khandekar,A., \& Sharma,A. (2006). Organizational learning and performance: Understanding the Indian scenario in present global context. Education \& Training, 48(8), 682-692.

Kossek, E. E., \& Block, R. N. (2000). Managing human resources in the 2 Ist century: From core concepts to strategic choice. Cincinnati, $\mathrm{OH}$ : Southwestern.

Kripalani, M., Engardio, P., \& Hamm, S. (2003, December 8). Cover story:The rise of India. Business Week, 386I, 66-76.

Kumar, S., Aquino, E. C., \& Anderson, E. (2007). Application of a process methodology and strategic decision model for business process outsourcing. Information Knowledge Systems Management, 6(4), 323-342.

Kwon, P. (2000). Hope and dysphoria:The moderating role of defense mechanisms. Journal of Personality, 67(2), 199-223.

Lee, T.W., Locke, E.A., \& Latham, G. P. (1989). Goal setting theory and job performance. In L.A. Pervin (Ed.), Goal concepts in personality and social psychology (Pp. 29I-326). Hillsdale, NJ: Erlbaum.

Locke, E.A. (1976). The nature and causes of job satisfaction. In M. D. Dunnette (Ed.), Handbook of industrial and organizational psychology (pp. 1297-1349). Chicago: Rand McNally.

Locke, E.A., \& Latham, G. P. (1990).A theory of goal setting and task performance. Englewood Cliffs, NJ: Prentice-Hall.

Lum, L., Kervin, J., Clark, K., Reid, F., \& Sirola,W. (1998). Explaining nursing turnover intent: Job satisfaction, pay satisfaction or organizational commitment? Journal of Organizational Behavior, 19(3), 305.

Luthans, F. (2002a). Positive organizational behavior: Developing and managing psychological strengths. Academy of Management Executive, 16(1), 57-72.

Luthans, F. (2002b). The need for and meaning of positive organizational behavior. Journal of Organizational Behavior, 23(6), 695-706.

Luthans, F. (2003). Positive organization behavior (POB): Implications for leadership and HR development and motivation. In R. M. Steers, L.W. Porter, \& G.A. Begley (Eds.), Motivation and leadership at work (pp. 187-195). New York: McGraw-Hill//rwin.

Luthans, F., Avey, J. B., Avolio, B. J., Norman, S. M., \& Combs, G. M. (2006). Psychological capital development:Toward a micro-intervention. Journal of Organizational Behavior, 27(3), 387-393.
Luthans, F., Avey, J. B., Clapp-Smith, R., \& Li,W. (2008). More evidence on the value of Chinese workers' psychological capital:A potentially unlimited competitive resource? International Journal of Human Resource Management, 19(5), 818-827.

Luthans, F., Avolio, B. J., Avey, J. B., \& Norman, S. M. (2007). Psychological capital: Measurement and relationship with performance and satisfaction. Personnel Psychology, 60(3), $54 I-572$.

Luthans, F., Avolio, B. J., Walumbwa, F. O., \& Li,W. (2005). The psychological capital of Chinese workers: Exploring the relationship with performance. Management and Organization Review, I (2), 247-269.

Luthans, F., \& Jensen, S. M. (2002). Hope:A new positive strength for human resource development. Human Resource Development Review, I (3), 304-322.

Luthans, F., \& Youssef, C. M (2004). Human, social, and now positive psychological capital management: Investing in people for competitive advantage. Organizational Dynamics, 33(2), I 143-160.

Luthans, F., Youssef, C. M., \& Avolio, B. J. (2007). Psychological capital. Oxford: Oxford University Press.

Martin, G., \& Beaumont, P. (1998). Diffusing best practice in multinational firms: Prospects, practice and contestation. International Journal of Human Resource Management, 9(4), 67I-694.

McGowan, M.A. (2004). Development of the recruitment value proposition for geocentric staffing. Thunderbird International Business Review, 46(6), 687-708.

Miller, J. (2003). Culture and agency: Implications for psychological theories of motivation and social development. $\ln \mathrm{V}$. Murphy-Berman \& J.J. Berman (Eds.), Cross-cultural differences in perspectives of the self (pp. 76-1 16). Lincoln: University of Nebraska Press.

Mody, A. (2004). What is an emerging market? (Working Paper, 04/177). Washington, DC: International Monetary Fund.

Nadkarni, S., \& Combs, G. M. (2006). Developing effective 360o feedback appraisals: A positive organizational behavior approach. Jigyasa: Journal of Human Resource and Organizational Development, Fall, 28-42.

Nag, B. (2004). Business process outsourcing: Impact and implications. Retrieved May 5, 2009, from http://www.unescap.org

Nelson, D., \& Cooper, C. L. (Eds.). (2007). Positive organizational behavior:Accentuating the positive at work. Thousands Oaks, CA: Sage. 
Nunnally, J. C., \& Bernstein, I. H. (1994). Psychometric theory. New York: McGraw-Hill.

Panayotopoulou, L., Bourantas, D., \& Papalexandris, N. (2003). Strategic human resource management and its effect on firm performance:An implementation of the competing values framework. International Journal of Human Resource Management, 14(4), 680-699.

Peterson, R. M., Dibrell, C., \& Pett, T. L. (2002). Performance perspectives of Western European, Japanese, and U.S. countries:Where do they lie? Journal of World Business, 37(4), 245-255.

Peterson, S. J., \& Luthans, F. (2003). The positive impact and development of hopeful leaders. Leadership and Organization Development Journal, 24(I), 26-3I.

Pio, E. (2007). HRM and Indian epistemologies:A review and avenues for future research. Human Resource Management Review, 17(3), 319-335.

Raman, S. R., Budhwar, P., \& Balasubramanian, G. (2007). People management issues in Indian KPOs. Employee Relations, 29(6), 696-710.

Seligman, M. E. P. (1998). President's column: Positive social science. APA Monitor, 29(4), 5.

Seligman, M. E. P. (2003). Foreword:The past and future of positive psychology. In C. L. Keyes \& J. Haidt (Eds.), Flourishing: Positive psychology and the life well-lived (pp. xi$x x)$. Washington, DC:APA.

Seligman, M. E. P., \& Csikszentmihalyi, M. (2000). Positive psychology. American Psychologist, 55(I), 5-14.

Sheldon, K. M., \& King, L. (200I).Why positive psychology is necessary.American Psychologist, 56(3), 216-217.

Singh, J. P. (1990). Managerial culture and work related values in Indian organizations. Organization Studies, I I ( I), 75-I0I.

Snyder, C. R. (2000). Handbook of hope. San Diego, CA:Academic Press.

Snyder, C. R., Cheavens, J., \& Michael, S.T. (1999). Hoping. In C. R. Snyder (Ed.), Coping:The psychology of what works (pp. 205-23I). New York: Oxford University Press.

Snyder, C. R., Feldman, D. B., Taylor, J. D., Schroeder, L. L., \& Adams, V., III. (2000). The roles of hopeful thinking in preventing problems and enhancing strengths. Applied and Preventive Psychology, 9(4), 249-269.

Snyder, C. R., \& Lopez, S. J. (Eds.). (2002). Handbook of positive psychology. Oxford: Oxford University Press.
Snyder, C. R., Sympson, S., Ybasco, F., Borders, T., Babyak, M., \& Higgins, R. (1996). Development and validation of the state hope scales. Journal of Personality and Social Psychology, 70(2), 32I-335.

Snyder, C. R., Tran, T., Schroeder, L., Pulvers, D., Adams, J., \& Laub, L. (2000). Teaching the hope recipe: Setting goals, finding pathways to those goals, and getting motivated. $\mathrm{Na}$ tional Education Service, 46-50.

Snyder, C. R.,Wiklund, C., \& Cheavens, J. (1999). Hope and success in college. Paper presented at the annual meeting of the American Psychological Association, Boston.

Sparrow, P., \& Budhwar, P. (1997). Competition and change: Mapping the Indian HRM recipe against world-wide patterns. Journal of World Business, 32(3), 224-242.

Srivastava, M. (2009, May 4). The sudden chill at an Indian hot spot. Business Week, 4I 29, 59-60.

Staats, S. R., \& Stassen, M.A. (1985). Hope:An affective cognition. Social Indicators Research, 17, 235-242.

Tapper, D. (2004). Worldwide and U.S. IT outsourcing services 2004-2008 forecast: A potential perfect storm (IDC Market Analysis Document 31089). Accessed from http://www. idc.com

Taylor, P., \& Bain, P. (2005). India calling to the far away towns: The call centre labour process and globalization. Work Employment \& Society, 19(2), 26I-282.

Tett, R. P., \& Meyer, J. P. ( 1993). Job satisfaction, organizational commitment, turnover intention, and turnover: Path analyses based on meta-analytic findings. Personnel Psychology, 46(2), 259-293.

Thite, M., \& Russell, B. (Eds.). (2009). The next available operator: Managing human resources in Indian BPO industry. New Delhi, India: Response Books from Sage.

Thorat, S. (2006, November 24). Higher education in India: Emerging issues related to access, inclusiveness and quality. Nehru Memorial Lecture, Mumbai, India.

Trompenaars, F., \& Hampden-Turner, C. (1998). Riding the waves of culture (2nd ed.). New York: McGraw- Hill.

Wright, P. M., Gardner,T. M., \& Moynihan, L. M. (2003). The impact of HR practices on the performance of business units. Human Resource Journal, 13(3), 2I-36.

Youssef, C. M., \& Luthans, F. (2007). Positive organizational behavior in the workplace:The impact of hope, optimism, and resilience. Journal of Management, 33, 774-800. 